\title{
The Scope of Tobacco Abuse in Kenya and Interventions Taken to Promote Cessation: A Review
}

\author{
Samuel K. Kirkok, Joshua K. Kibet \\ Department of Chemistry, Egerton University, Egerton, Kenya \\ Email: *jkibet@egerton.ac.ke
}

How to cite this paper: Kirkok, S.K. and Kibet, J.K. (2019) The Scope of Tobacco Abuse in Kenya and Interventions Taken to Promote Cessation: A Review. Open Access Library Journal, 6: e5578

https://doi.org/10.4236/oalib.1105578

Received: July 4, 2019

Accepted: August 3, 2019

Published: August 6, 2019

Copyright $\odot 2019$ by author(s) and Open Access Library Inc.

This work is licensed under the Creative Commons Attribution International License (CC BY 4.0).

http://creativecommons.org/licenses/by/4.0/ (c) (i) Open Access

\begin{abstract}
Studies have revealed that the prevalence of tobacco abuse in Kenya has continued to rise sharply over the past few years hence causing worries among health providers and agencies mandated to deal with drug abuse. Various reports and surveys by international and local agencies have conducted researches that underscore this observation. The economic burden associated with ailments from tobacco abuse in Kenya is enormous. This review explores the scope of tobacco abuse in Kenya; loss of livelihoods as well as the health implications and disease burden. Published articles were identified using electronic searches such as Google scholar, government reports, case studies and Web of Science. Most of the eligible articles were those published between January 2000 and October 2018. The considered studies were evaluated against the norms drawn from the Cochrane Reviewers' Handbook version 5.0.0. The existing facts on tobacco use by gender in Kenya show that $15.1 \%$ of the current tobacco users were men while women constituted $0.8 \%$. It is estimated that the Kenyan government spends an outrageous 15 bn Kenyan shillings (KES) in mopping up the effects of tobacco abuse annually. The common smoking cessation approaches mainly employed are community-based interventions and media campaigns with very minimal use of medical interventions. Kenya has tried to control tobacco abuse through legislation such as the formulation of the 2007 Tobacco control act (TCA). Knowledge on tobacco has been enhanced through research, tobacco promotion and sponsorship (TAPS), international tobacco control (ITC), Kenya demographic health survey (KDHS) and Global adult tobacco survey (GATS). Despite these efforts, statistics show a worrying trend in tobacco use among the young Kenyan population with several studies confirming increase in tobacco use among this category of the Kenyan population. Consequently, expenditure arising from tobacco abuse has sharply increased both nationally and at
\end{abstract}


the individual level.

\section{Subject Areas}

Health Policy

\section{Keywords}

Tobacco Abuse, Kenya Demographic Health Survey, Economic Burden

\section{Introduction}

Close to 8 billion cigarette sticks are consumed in Kenya annually according to a statistical report by the World Health Organization (WHO) [1]. Currently, Kenya's population is estimated at 50 million implying that cigarette smoking in Kenya may have increased to about 10 billion sticks annually. This translates to a financial burden of approximately 40 billion Kenya shillings (KES) - money that would have otherwise been used in providing essential services to Kenyans thereby improving their standards of living. This unfortunate expenditure on cigarette smoking and tobacco abuse is a precursor for disease and poverty among the Kenyan communities [2]. The 2014 Global adult tobacco survey reported the prevalence

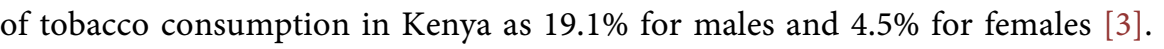
On the other hand, Lore's survey on health care workers in Kenya reported a "current smoking" prevalence of 54\%, with males predominating (63.9\% of all subjects sampled) [4]. Kwamanga and others (2003) found a prevalence rate among primary school teachers of $50 \%$ in males and $3 \%$ in females $(n=813)$ [5] [6]. Statistics from the Global Youth Tobacco Survey conducted in 2007 revealed that $18.5 \%$ of the youth aged between 13 and 15 used tobacco products [7].

A study that was conducted in 2008 revealed $19 \%$ of males and $2 \%$ of females smoke tobacco [8]. Central province showed tobacco prevalence of 30.4\%, Eastern Kenya 26\%, Coastal region $22.6 \%$, Nairobi city $17.1 \%$, North Eastern region $15.6 \%$, the larger Rift valley $14.3 \%$, Western Kenya $11.2 \%$ whereas prevalence of cigarette smoking in the larger Nyanza region was reported to be the lowest at 7.9\% [9]. Menthol and sweet menthol cigarettes were reported to be popular with males in Kenya compared to male cigarette smokers in other international tobacco control (ITC) approved countries [10]. The use of flavoring in cigarettes is a threat to tobacco control measures because it is reported that flooring provides a smooth sensation to the respiratory system thus leading to heavy smoking [10]. Most female smokers, for fear of stigmatization do not reveal their smoking status. This made the findings from this study biased towards the male counterparts [11]. Another study by the Kenya Global Youth Tobacco Survey that was done in 2001 reported that among school going children, 13\% of these children aged between 12 - 15 years used tobacco products. $7.2 \%$ constituted those that smoke tobacco while $8.5 \%$ were found to use other forms of tobacco such as sniffing [12]. Another survey targeting students was done in 2007. The 
findings indicated that $18.2 \%$ of boys and $18.2 \%$ of girls constituting an overal $18.6 \%$ of the students abused any tobacco product. The current standing of tobacco smokers was at $9.8 \%$ while $12.8 \%$ were found to use other forms of tobacco such as sniffing [12]. The findings of the study also revealed a $43 \%$ increase in tobacco use among children [4]. The Increase in boys was reported to stand at $15.2 \%$ compared to that of girls which was noted to be $82 \%$ increase in a period of six years. Smoking prevalence among the school going children over the same period was revealed to stand at $77.8 \%$ [4]. The passing of the Tobacco Control Act (TCA) of 2007 and the ratification of FCTR (2004) by WHO has made Kenya to make major strides in tobacco control [13]. TCA was passed by the Kenyan parliament and governs tobacco control abuse in Kenya. Its main objective was to support research and dissemination of information to the general public. Through tobacco control action plan, it has been relatively easy for Kenya to monitor the implementation of the recommendations of TCA as enshrined in the public health policy. Of great importance in the act are the findings through research, monitoring of progress and assessment of the dangers of tobacco abuse and tobacco quitting strategies [13].

Research findings from various studies on tobacco use paints at a rapid increase in tobacco use among the young people [13]. The increase was marginal in the boy child but significant in the girl child [8]. Remarkably, adults were reported to start smoking immediately they attain adolescent age [14]. Adults who start smoking at younger age tend to have ill health and are prone to diseases related to heavy tobacco smoking [15]. Government agencies such as the National agency for the campaign against drug abuse (NACADA), international researchers and non-government organizations and agencies such as the world health organization (WHO) and the centre for disease control, and prevention(CDC)have done several researches on tobacco use among a country's population as well as in special groups such as students and women [8]. The Kenyan situation analysis by the Kenya tobacco situation analysis (KTSA) which was done between 2008 and 2010 revealed that the country has not put enough effort in tobacco control, enforcement and follow up of the current tobacco legislation policies [16]. In another study which was conducted in 2011 with the sole aim of assessing the progress made by the government in the implementation of the Frame Work Convention on Tobacco control (FCTC) and the implementation of the Tobacco Control Act (TCA) of 2007 [17]. The study reported that significant steps were taken into account during the implementation of the programs. Unfortunately, most activities were taken up by the health ministry with little participation from other Government ministries [15]. Limitation of incomes and industry meddling were mentioned as blockades to progress in tobacco control and cessation [12].

\section{Methodology}

In this review, published articles, technical reports and various survey findings 
from the ministry of health were considered. Information was also obtained from the internet by doing a search using advanced Google scholar, Web of Science, Sci-Finder and Cochrane literature search engines. These sources were chosen because they were wide-ranging and contained up to date reports from studies conducted in Kenya and around the world. Moreover, direct searches from open access journals were also explored. The search items included the combinations: "Kenya and smoking", "Smoking cessation", "Kenya tobacco policy" and "tobacco abuse in Kenya". Titles of the articles were read in order to identify those whose studies focused on the Kenyan situation analysis. Abstracts were also reviewed; articles whose abstracts focused on tobacco use, use of tobacco products, smoking cessation strategies were included in this study. More than 150 articles were reviewed out of which 50 articles were found to be suitable for this review. Articles were eligible for review if they were in English original-surveys and/or research papers and focused on the scope of tobacco abuse in Kenya, legislative policy on tobacco abuse and economic consequence of tobacco use, and health related aspects. Studies conducted between 2000 to date were captured in this review. Additional articles for inclusion were identified by searching the references of the eligible articles. The search for eligible articles yielded articles in English in order to minimize challenges arising from language barriers.

The authors read through all the articles or research findings from the search on the internet meticulously. Those articles that contained irrelevant or insufficient information were discarded or excluded. Relevant articles were individually assessed by the authors. The key emphasis was to ensure that all articles to be considered met the important inclusion criteria. Individual author's opinion on articles' eligibility was sort by convening a meeting of authors to ensure a critical review. Decisions were based on inclusion criteria such as the scope of the study, composition of participants, interventions, and expected outcome. Disparities in authors' judgements were fixed through discussion and compromise mechanisms. The flow diagram presented in Figure 1 outlines the steps taken in choosing the articles for this review article.

Out of the 24 articles reviewed, two were studies on tobacco abuse by youth, 6 were articles on tobacco cessation mechanisms and cessation challenges. The technical reports and surveys reviewed were three (3); Tobacco, promotion and sponsorship (TAPS), International tobacco control (ITC) Kenya, Kenya Demographic Health Survey (KDHS) and Global adult tobacco survey (GATS). Three were on state of tobacco use in Kenya. The remaining eleven articles focussed on tobacco consumption and related health implications (Table 1 and Table 2). The article extracted mainly included; sample size, location or region of participants, sample size, age of the respondents and their smoking characteristics of respondents. Initial search yielded 150 articles, 100 of these articles were removed because they were found to be duplicated. After scanning the titles and abstracts, a further 19 articles were excluded. After reading the full texts of the remaining articles 24 articles were found to fully meet eligibility criteria. 


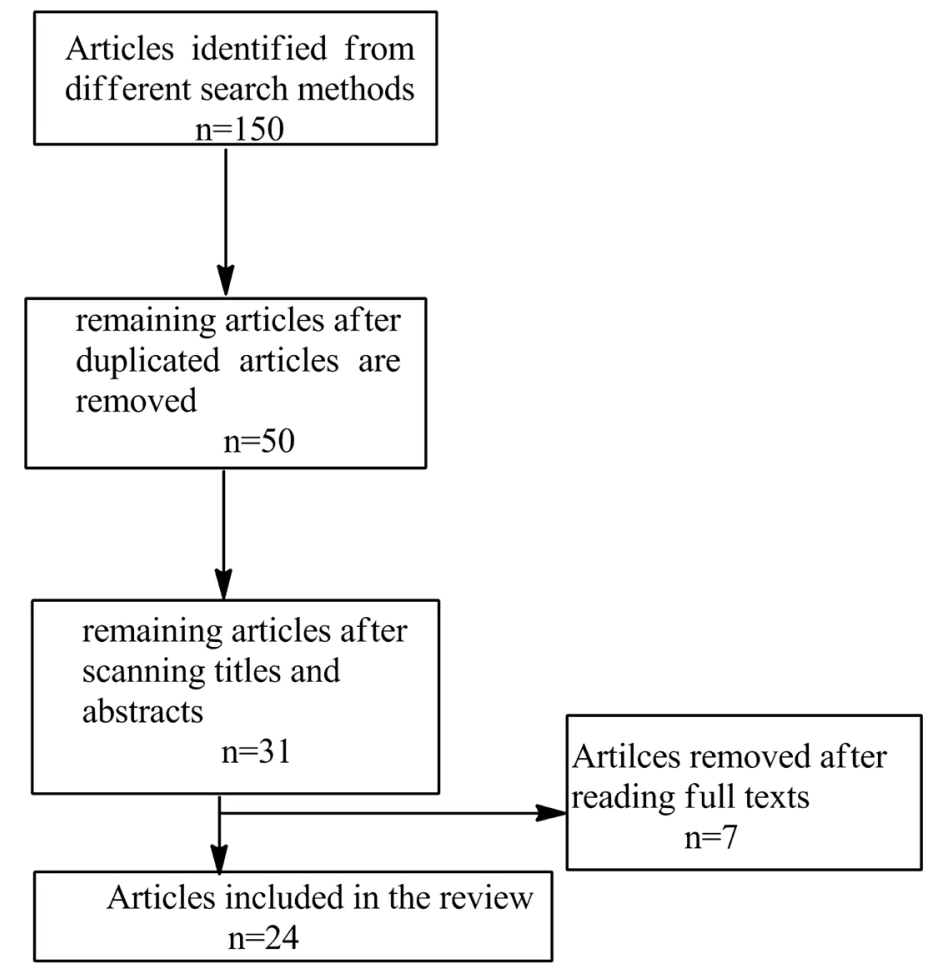

Figure 1. Flow chart of literature search.

Table 1. Statistics on tobacco consumption in Kenya.

\begin{tabular}{cccccc}
\hline Author & Region of study & Design & Age & Incidences of tobacco use population \\
\hline$[21]$ & Nairobi & Tobacco smoke & $12-17$ & $31 \%$ & 1130 \\
{$[5]$} & Nairobi & Tobacco smoke & Mean 16.7 & $32 \%$ & 5311 \\
{$[13]$} & National & Tobacco smoke & $13-15$ & $21.2 \%$ & 6768 \\
{$[8]$} & National & Products of tobacco & $14-23$ & 18.3 & 458 \\
{$[22]$} & Eldoret & Cigarette use & $18-32$ & $42.8 \%$ & 500 \\
\hline
\end{tabular}

Table 2. Incidence of tobacco abuse.

\begin{tabular}{cccccc}
\hline Author & $\begin{array}{c}\text { Region of } \\
\text { study }\end{array}$ & Design & Age & $\begin{array}{c}\text { Percentage incidences } \\
\text { of tobacco abuse }\end{array}$ & $\begin{array}{c}\text { Sample } \\
\text { population }\end{array}$ \\
\hline$[15]$ & National & Tobacco smoke & average 16.7 & $10.5 \%$ & 5311 \\
{$[6]$} & National & Tobacco smoke & $13-15$ & $8.2 \%$ & 6768 \\
{$[23]$} & National & Tobacco products & $15-49$ & $19 \%$ & 18,503 \\
{$[24]$} & Nairobi & Tobacco smoke & Pupils & $12.1 \%$ & 281 \\
{$[25]$} & Rural & Products of tobacco & Children & $3.8 \%$ & 800 \\
{$[26]$} & National & Products of tobacco & $15-65$ & $9.1 \%$ & 2580 \\
\hline
\end{tabular}

\section{Results}

Studies indicate that smoking prevalence among the Kenyan adult population shot up from $6.6 \%$ in 2001 [18] to $18 \%$ in 2008 [19]. Of more concern, however; 
are the findings of similar studies conducted among students in the country which indicate an exponential increase in smoking prevalence from $8.2 \%$ in 2007 to $58 \%$ in 2012 [18]. The above situation has led many scholars to endeavour to understand the factors that have culminated to the increase in smoking prevalence among the younger generation [18]. Doubts have been cast on the effectiveness of taxation policies on tobacco abuse [20].

\subsection{The Kenyan Status on Tobacco Use}

The prevalence of tobacco is reported in Table 1. All studies were conducted within a population of ages between 12 and 32 . Two of the studies had national representative sample while one study investigated the use of tobacco products while other three studies explored the impacts on cigarette abuse.

Incidences of tobacco use were found to range from 3.8\% - 19\% (Table 2). The studies revealed that the prevalence of tobacco consumption was higher in urban area than in rural area [15]. This review showed that three quarters of previous studies focused generally on tobacco abuse.

Most of the studies included in this review were cross-sectional surveys. The focus of three studies was generally on substance abuse without necessarily dealing on tobacco abuse. KDHS survey focussed generally on the health status [27] whereas most of the studies considered tobacco control and the general consumption tobacco abuse. Three studies were conducted by the government and therefore had national representative surveys on tobacco use [28]. The global youth tobacco survey (GYTS) focused on tobacco abuse specifically on matters concerning publicity health and exposure to tobacco promotion, attitudes and insight into tobacco use, and quitting [18]. Two of the national studies, however; did not focus on tobacco use [15]. Besides, the three studies used different age groups therefore making comparison impossible. Majority of the studies were conducted among the younger population. This underscored the facts in literature that tobacco use probably begins at the tender age [25]. Such studies are more popular because of the ease of conducting school based surveys than community based surveys [27]. Similarly, findings from school based surveys are more reliable than household studies [21].

\subsection{Tobacco Control Act (TCA) 2007}

The TCA was passed by the Kenyan legislatures in 2007 despite opposition from tobacco companies. The main purpose of the act was to control the production, labelling of tobacco as a dangerous substance and promotion of tobacco cessation [13] [29]. The Act explains the role the Kenyan government in the control of cigarette sales and consumption of tobacco related products in the country. This Act is divided into seven parts [17]. Part three of the act describes the need to disseminate information and educate the public regarding the addictive nature and health threats caused by smoking [15]. The primary focus of the education component in the act is to reach out to the family as well as in schools and 
other institutions of learning on the dangers of tobacco abuse [30]. Part four of the act aims at controlling the sale of tobacco products in the Kenyan market-this includes barring trading in or distribution of tobacco products to any person below the age of 18 and also bans the sale of single stick cigarettes [9]. Part six of the tobacco control act protects the public from involuntary exposure to tobacco smoke by prohibiting smoking in all public places [29]. Despite the enactment of the TCA, most of its specifications are yet to be fully enforced and no one has been prosecuted for violating the act. The delay in the implementation of the TCA legislation has been mainly attributed to the resistance of tobacco companies to conform to the specifications outlined in the act, as well as the laxity on the part of the government to enforce the law [1]. Moreover, the judicial system in Kenya has not been keen to prosecute any offenders acting in contravention of the act. Due to these lapses in implementation of the act, consumption of tobacco has persisted and is sharply increasing among Kenyans of all ages, gender and social status [25].

\subsection{The Health Sector in Kenya with Respect to Tobacco Smoking}

According to the Kenya health policy 2012-2030, health is one of the key components of delivering the Vision's social pillar given the key role it plays in maintaining a healthy and skilled workforce necessary to drive the economy [31]. The Kenya government unfortunately spent a huge budget of approximately 34.7 bn KES for the 2013/2014 financial year for preventive and curative health services and a large portion of this was spent on the non-communicable diseases (NCDs) [17]. The total health expenditure per capita was US $\$ 27$ while the government health expenditure was 5.2\% of total budget in 2016 [31]. 31\% of the total health expenditure was provided by donors although Kenya is yet to reach the $15 \%$ of the GDP to be used on health as agreed in the Abuja convention of 2010 [32]. Tobacco use is a risk factor which either increases the risk or causes most of the NCDs [9]. A decade ago, tobacco accounted for almost 6 million deaths every year (including over 600,000 deaths from exposure to second hand smoke) and was projected to increase to 8 million deaths annually by 2030 [16]. Tobacco use is ranked second with $9 \%$ of global deaths attributed to it (CDC, Global Youth Tobacco Surveillance, 2000-2008) [21]. Centers for disease control and prevention (CDC) conducts global adult tobacco survey (GATS) in all the countries every 4 years to check the situation in every country with respect to tobacco use and cessation [16]. GATS is the global standard to systematically monitor adult tobacco use and track key tobacco control indicators [16]. GATS is a national representative household survey of persons above 15 years of age that uses a standard protocol [20]. The intention of GATS is to generate comparable data within and across countries [16]. GATS enhance countries' capacity to design, implement and evaluate tobacco control interventions [16]. GATS has been carried out in a number of countries in Africa including Egypt, Nigeria and Kenya [9]. According to the Kenyan fact sheet, it was found 
out that $15.1 \%$ of the current tobacco users were men with only $0.8 \%$ being women [20]. The overall former daily tobacco smokers were found to be $28.5 \%$ implying that over a quarter of the Kenyan population is either using tobacco or have previously used tobacco and/or tobacco related products [30].

\subsection{International Tobacco Control (ITC) Kenya Survey}

The ITC Kenya Survey data suggest that tobacco use has increased based on the Kenya Demographic Health Survey (KDHS) conducted between 2008 and 2009 which found that $19 \%$ of men and $1.8 \%$ of women were to baccousers [15]. The ITC Survey conducted in 2012 found that $16 \%$ of adults in Kenya-27\% of which were men and $5 \%$ women were consumers of tobacco products [33]. Tobacco use prevalence ranged from $9 \%$ in Western and Nyanza provinces to $26 \%$ in Coast province [33]. The types of tobacco products used differed among men and women - the majority of male tobacco users (83\%) mainly use smoked tobacco products (primarily cigarettes) while female tobacco users (66\%) mainly use smokeless products [26]. The majority of Kenyan cigarette smokers use factory-made cigarettes $(87 \%)$ whereas $12 \%$ smoke hand-rolled cigarettes and the rest $1 \%$ smoked both forms of cigarettes [30]. More than one-third (40\%) of Kenyan smokers have "ever" tried to quit smoking cigarettes, and $17 \%$ of smokers planned to quit in the next 6 months [6]. Concern for serious tobacco illnesses such as cancer and respiratory diseases informed the decision to quit cigarette smoking for good. Smokeless tobacco users were even less likely to have attempted to quit-about one-fifth (21\%) of smokeless users have tried to quit [34]. The two most common reasons advanced for the desire to quit smokeless tobacco were the same as those for smokers [31]. Of concern is the finding that the price of cigarettes and smokeless products were among the least frequently cited reasons influencing quitting [5]. Tobacco users in Kenya are not well connected to information about tobacco cessation assistance [9]. One-fifth (20\%) of tobacco users reported that they had visited a doctor or some health provider in the last 6 months [6]. Among smokers who had visited a doctor, 35\% were given advice to quit tobacco-a lower percentage than in most of the other ITC low middle income countries (LMICs) [9]. It is well established that advice to quit from a physician or health provider is a powerful precursor towards achieving tobacco cessation [5]. Of those who were given advice to quit, $82 \%$ reported that the advice made them ponder seriously about quitting tobacco [6].

\subsection{The Kenya Demographic and Health Survey (KDHS)}

The Kenya demographic and health survey (KDHS) measured tobacco use among a nationally representative sample of adults in 2003 and repeated the survey in 2008-09 period [30]. In the KDHS, adult men and women were asked whether they smoked cigarettes or used any other tobacco products [19]. The survey findings showed a decrease in all types of tobacco use among men aged between 15 - 49 years from $25 \%$ in 2003 to $19 \%$ in $2008-09$ periods [19]. Ciga- 
rette smoking among males also decreased from $23 \%$ in 2003 to $18 \%$ in 2008-2009 [15]. Among women, tobacco use of any kind continued to be low at less than 3\% in 2003 and less than 2\% in 2008-09 [30]. Rates of cigarette smoking among women remained the same in both surveys; at less than $1 \%$. In 2008-09, the highest cigarette smoking prevalence rate was among men aged 45 $49(29.6 \%)$ [19]. Male respondents who were more educated and who were in the highest wealth quintile were less likely to smoke [30]. Conversely in 2003, men with no education were less likely to smoke and those in the lowest and middle wealth quintiles were less likely to use tobacco products [15]. In both surveys, men with no education had the highest rate of using other tobacco products besides cigarettes or pipes (15.8\% in 2003 and $18.3 \%$ in 2008-09) [18]. In 2008-09, Central province of Kenya had the highest rate of male cigarette smokers (30.4\%), while in 2003 Eastern province had the highest rate of male cigarette smokers (37.1\%) [35]. Nyanza province had the lowest rate of smoking among men at $7.9 \%$ in $2008-09$ and $11.0 \%$ in 2003 [15].

\subsection{The Global Adult Tobacco Survey (GATS)}

The global adult tobacco survey (GATS), a nationally representative survey of adults across countries was conducted in Kenya in 2014 [36]. The survey found that the prevalence of any tobacco use among men has remained the same at $19 \%$ since the survey was conducted between 2008 and 2009 by KHDS [30]. The rate of cigarette smoking among men had declined slightly, from 18\% in 2008-09 to $15 \%$ in 2014 [36]. Tobacco use among women increased slightly from less than $2 \%$ in $2008-09$ to $4.5 \%$ in 2014 although cigarette smoking among women remained the same at less than $1 \%$ [36]. GATS found that the majority of adult Kenyan tobacco users were smokers. Accordingly, $61 \%$ of tobacco users used smoked tobacco, 33\% used smokeless tobacco while $6 \%$ were hybrid users [22]. The majority of smoked tobacco users were men (72\%) whereas $16 \%$ were women and $83 \%$ of smokeless tobacco users were women while $21 \%$ were men [36].

\subsection{Tobacco Cessation and Its Benefits}

Smoking cessation refers to discontinuation of smoking or inhalation of tobacco products or quitting smoking for good [37]. Tobacco cigarette smoking is a medical condition that is normally considered chronic and if not properly managed, may results to a greater chance of relapsing [38] [39]. Most smokers are aware that smoking is harmful although many have tried more than once to attempt to quit [40]. Regrettably, above $80 \%$ of those who attempt to stop tobacco smoking find themselves relapsing to the same smoking habits [41] [42]. There are many associated benefits in quitting tobacco smoking; notably, improved health and reduced risk commonly associated with tobacco smoking diseases [43]. Quitting smoking is a slow process that involves stepwise consistent reduction of the urge to smoke; it is not an instant abstinence, but the benefits are 
immediate and possibly realized in less than a month after quitting [38]. Quitting smoking has benefits such as reduction of risk of diseases such as cancer of the oesophagus and lung cancer [44]. Smoking has been found to decrease life expectancy. Life expectancy is reported to be enhanced by smoking cessation [37]. It is thus of critical significance that smokers get access to smoking cessation interventions and treatment. This encourages people to stop smoking and therefore exploit the smoker's probabilities of abandoning cigarette smoking successfully [43].

\subsection{Interventions for Tobacco Cessation}

Smoking cessation can be achieved through telecoms, media, and technology (TMT)-based interventions, behavioral or pharmacological interventions [9]. Behavioral interventions when used together with medication yields a high rate of successful smoking cessation [45]. Behavioural interventions involve counselling sessions by health providers as well as providing routine advice and consultations which are provided resourcefully to smokers [43].

Pharmacological interventions are a combination of two pronged mechanism include both nicotine based and non-nicotine based medications [43]. Nicotine replacement therapies (NRTs) are a pharmacological method that is normally approved by food and drug administration (FDA) [45]. NRT is known to exist in the following forms; nicotine patches, chewing gums, nasal sprays, inhalers and tablets [34]. The sole objective of NRT is to replace nicotine obtained from cigarette smoking and therefore lower the urge to smoke therefore making quitting cigarette smoking relatively easy [45]. Apart from NRT, other non-nicotine medications involve the use of bupropion or varenicline which have proved quite effective [34]. Bupropion has been found to lessen the desire to smoke cigarettes in clinical trials [43]. Bupropion works by inhibiting dopamine re-uptake into neuronal synaptic vesicles in nucleus accumbens [45]. Varenicline has been reported to be very effective and its mechanism of action involves stimulating and blocking of nicotinic receptors in the brain [46].

Price-based policy measures used by most governments include raising taxes on tobacco products [9]. Studies have shown that $10 \%$ increases in tax on cigarette price reduce smoking occurrence by between $4 \%$ and $8 \%$ [37]. It is also reported that public benefits from tobacco tax remain positive only when tax rates are in the range $42.9 \%$ and $91.1 \%$ [13].

\section{Discussion}

The deliberate use of mass media to deliver campaign messages against cigarette smoking as well as health consequences of tobacco smoking is effective in reducing smoking prevalence [15]. Telecommunication and technology based interventions are becoming popular in disseminating cautionary messages against smoking. They are effective and widely used due to their universal reach and low implementation costs. Online campaign have also proven to be more cost effec- 
tive than other media, though doubts are cast on its effectiveness in reducing smoking prevalence especially among the illiterate population [9]. Framework convention on tobacco control (FCTC) is the world's first most successful public health treaty established by WHO to fight the global tobacco menace through various measures that include advocacy for reduction of tobacco demand and supply through control of tobacco pricing and taxation, advocacy for smoke-free policies, packaging and labelling of tobacco products, tobacco advertising and sponsorship, cessation and treatment, illicit trade and sales of tobacco products to minors.

Statistics from various surveys in Kenya show a rapid surge in tobacco use predominantly among the youth. The increase was reported to be even more prevalent in girls as compared to boys [8]. It is reported that most adults who smoke started as teenagers [47]. Those persons who start smoking at tender age eventually become heavy smoker at the adult age. The consequence of this is ill health especially from ailments related to cigarette smoking. Several studies have established that exposure to cigarette smoking causes a number of ailments that includes coronary ailments, cancers and chronic lung diseases [33]. It well-known that smokers are more likely to have ill health than non-smokers because they spent most of their time seeking treatment resulting to a greater financial burden than non-smokers [48].

The families of heavy smokers are accordingly subjected to economic stress when smokers are hospitalized and thus resources will have to be mobilized to meet medical bills [9]. The economic productivity of smokers also deteriorates due to nonattendance to productive engagements and economic losses in meeting direct medical costs [9]. The suffering due to pain, distress and low quality of life are other indiscernible costs that cannot be quantified. Scientific statistics reveal that chronic diseases contribute about $50 \%$ of all hospital admissions in Kenya [18]. They are also reported to cause over $30 \%$ of total deaths [9]. Smoking related diseases overstretches the health system that is also overburdened by communicable diseases [31]. Continued use of tobacco will worsen this state in future because tobacco associated diseases continue to occur and may become resistant to medications [9].

Tobacco business is counter-productive to the health status of a country. It is estimated that for every dollar earned from tobacco revenue, three dollars are used to mop up tobacco related ailments [31]. For instance, Kenya gathers about 5 billion shillings every year as tobacco proceeds but ends up susing 15 billion shillings to treat tobacco related diseases in the country [17]. Tobacco farming and production is a rigorous agricultural practice especially in terms of labor. Studies have revealed that tobacco farming apart from being labor intensive affects the educational levels of girls their nutrition and general reproductive health of women. This is because girls and women labor are extensively used in tobacco production [17]. Tobacco farming degrades soil productivity. It has detrimental effects on the environment consequently hence causing reduction in 
food productivity and thus food insecurity. This frustrates government's efforts to eradicate poverty [23]. Tobacco farming causes serious destruction of biodiversity, fertilizers and chemicals used to spray tobacco plants cause deadly environmental impacts [23]. Similarly, wood is used as fuel when curing tobacco leaf-this is a deadly precursor for forest destruction by deforestation thus leading to reduction in forest cover [8].

Tobacco control legislation attempts to discourage or stop people's exposure to cigarette smoke in the community through its prescribed programs. This prevents the young people from indulging into the network of smokers. Legislation therefore enhances tobacco cessation efforts thereby increasing the chances of quitting tobacco use by tobacco users. People's health will thus improve and health inequalities will increase [6]. Tobacco smoking largely contributes to the already widening gap in life expectancy among a country's population [14]. Therefore, it important to target the socially disadvantaged persons in the society when designing tobacco control programs [17].

The World health organization framework convention on tobacco control (WHOFCTC) encompasses six policy measures, currently known as MPOWER which is an abbreviation for monitor, protect, offer, warn, empower and raise-monitoring tobacco use and interventions, protecting people from tobacco smoke, offering help to quit tobacco use, warning against the dangers of tobacco, enforcing bans on tobacco advertisements, tobacco promotion and sponsorship (TAPS), raising taxes on tobacco, and other tobacco supply-reduction measures, including developing sustainable alternatives to tobacco-growing, controlling illicit trade and regulating tobacco products which are intended to assist in the implementation of effective interventions with the primary focus of reducing the demand and supply of tobacco products at the country level [16]. Presently, over 2.3 billion people in 92 countries are subscribing at least one of the MPOWER measures [16]. In Kenya, despite the enactment of the tobacco control act of 2007, the prevalence of tobacco abuse keeps rising at an alarming rate and has massively been regarded as one of the main public health concerns [49].

An assessment of the implementation of tobacco control policies in Kenya was carried out by WHO in 2011 [16]. The goal of the assessment was to look at the status of the implementation of tobacco control measures and assess the Kenyan capacity to implement the provisions of the framework convention on tobacco control (FCTC) [15]. The findings of this study was consistent with those of previous studies with found out coordination among the players in tobacco control has been missing [47]. Measures such as use of pictorial cautions in cigarette packets had also not been implemented [15]. Nevertheless, there has been substantial development in studies on the monitoring of implementation of the FCTC and the TCA [17]. Moreover, there is steadiness in the obstacles that deter operative implementation of tobacco control policies [44]. These include tobacco industry meddling and lack of organization mechanism among government agencies that are concerned with drug abuse [31]. As a result of the wide-ranging 
nature of the TCA and FCTC, no study gave details on a precise provision for the execution of tobacco cessation strategies [15]. Nonetheless, none of the studies highlights the effectiveness of the FCTC and TCA on tobacco use and tobacco associated health impacts [31]. These developments have made it necessary to change from studies that monitor progress to studies that evaluate the impact of implementation of tobacco control act (TCA) and other tobacco cessation strategies [17].

In this review, there are two studies that researched on tobacco, promotion and sponsorship (TAPS) from two diverse standpoints [16]. The first looked into the sources of pro and anti-tobacco exposure messages in primary school going children [35]. This study was done before the enactment of the tobacco control act that banned TAPS. The study established that tobacco publicity was a risk factor in cigarette smoking [35]. The second study was conducted over a period of two years focussed media monitoring concerning tobacco, promotion and sponsorships (TAPS). Notwithstanding the establishment of the TCA, it revealed that the tobacco industry was dubious techniques to circumvent the established laws that prohibit unconventional means to encourage people to smoke [15]. In 2007, a study was conducted to examine the support tobacco control policies gets from the public and to assess how the findings could be used as a catalyst to the legislative process especially the establishment of tobacco control law in the country [15]. This formed the best examples of employing scientific studies to inform policy. This study and its findings were instrumental in the passing of the tobacco control act (TCA) by the Kenyan parliament [26]. Studies on policy are vital because they provide evidence to the tobacco industry against tobacco control [9]. Evidence-based policy adoption is important inreducing the burden related with tobacco use more so in the world's poorest economies [50].

\section{Strength and Limitations of the Study}

$>$ This study has provided tobacco abuse situational analysis in Kenya, provided statistics on tobacco smoking and the efforts the government has put in place to control tobacco abuse. This paper therefore can form a point of reference on matters tobacco abuse in Kenya and may apply to other countries of similar experience.

> Most of the articles did not qualify for use in this review because they had no relevance to the Kenyan context and were therefore excluded. The articles might have had critical information on tobacco use but failed to capture the scope and relevance of tobacco abuse and cessation strategies in Kenya.

$>$ It is evident from this review that few studies have been conducted on tobacco abuse and measures undertaken to promote tobacco cessation in Kenya.

> This review article makes detailed exposition on the major gaps in policy implementation towards curbing tobacco control and abuse in Kenya.

Despite the passing of the TCA in 2007 and the ratification of FCTC, tobacco abuse in Kenya is still alarming. 


\section{Conclusion}

This review article has established that although the Kenya government has made some strides in the control of tobacco abuse, the prevalence is still very high. The formulation of the tobacco control act of 2007 and the ratification of FCTC in 2004 were key steps towards tobacco control and promotion of tobacco cessation but these have not realized significant progress so far. On the contrary, more youth and adults have been recruited into cigarette smoking and tobacco abuse. Ailments arising from tobacco use have significantly burdened the economy in terms of medication and loss resulting from death as well as impoverishment of a large portion of the Kenyan population courtesy of tobacco abuse and tobacco related diseases such as cancer. The health care providers have done little in terms of providing smoking cessation interventions especially pharmacological and counseling interventions. Lack of these services coupled with intermittent mass media campaigns against tobacco use has made quitting rates very low. Studies on the psychological effects of tobacco consumption in Kenya and the health consequences of tobacco smoking are rare. This review study therefore has identified gaps in tobacco research in Kenya that may be beneficial towards tobacco cessation.

\section{Acknowledgements}

The authors are grateful to Egerton University, the division of research and extension for facilitating the success of this article.

\section{Ethical Considerations}

Not applicable.

\section{Conflicts of Interest}

The authors declare that they have no competing interests regarding the publication of this article.

\section{References}

[1] WHO (2010) Hidden Cities: Unmasking and Overcoming Health Inequities in Urban Settings. WHO, UN Habita, Kobe, 1-145.

[2] Zhang, E., Tu, W. and Kleinman, A. (2010) Depoliticizing Tobacco's Exceptionality: Male Sociality, Death, and Memory Making among Chinese Cigarette Smokers. In: Governance of Life in Chinese Moral Experience, University of Chicago Press, Chicago, 85-109. https://doi.org/10.2307/20066308

[3] Gichuki, J.W., Opiyo, R., Mugyenyi, P. and Namusisi, K. (2015) Healthcare Providers' Level of Involvement in Provision of Smoking Cessation Interventions in Public Health Facilities in Kenya. Journal of Public Health in Africa, 6, 523. https://doi.org/10.4081/jphia.2015.523

[4] Lore, W. and Lwenya, R. (1988) Smoking Habits in Kenya. II. A Follow up Study Involving Personnel Working at Kenyatta National Hospital, Nairobi. East African Medical Journal, 65, 71-80. 
[5] Kwamanga, D., Odhiambo, J. and Gicheha, C. (2001) Tobacco Consumption among Primary School Teachers in Nairobi. East African Medical Journal, 78, 119-123. https://doi.org/10.4314/eamj.v78i3.9075

[6] Nturibi, E.M., Kolawole, A. and McCurdy, S.A. (2009) Smoking Prevalence and Tobacco Control Measures in Kenya, Uganda, the Gambia and Liberia: A Review. International Journal of Tuberculosis and Lung Disease, 13, 165-170.

[7] Maina, W.K., Nato, N.J., Okoth, M.A., Kiptui, D.J. and Ogwell, A.O. (2013) Prevalence of Tobacco Use and Associated Behaviours and Exposures among the Youth in Kenya: Report of the Global Youth Tobacco Survey in 2007. Journal of Public Health Research, 3, 43-49.

[8] Kaplan, M., Carriker, L. and Waldron, I. (1990) Gender Differences in Tobacco Use in Kenya. Social Science \& Medicine, 30, 305-310. https://doi.org/10.1016/0277-9536(90)90186-V

[9] Ekpu, V.U. and Brown, A.K. (2015) The Economic Impact of Smoking and of Reducing Smoking Prevalence: Review of Evidence. Tobacco Use Insights, 8, 1-5. https://doi.org/10.4137/TUI.S15628

[10] WHO (2007) The Scientific Basis of Tobacco Product Regulation. Vol. 945. http://www.who.int/tobacco/global_interaction/tobreg/who_tsr.pdf

[11] Mpabulungi, L. and Muula, A.S. (2004) Tobacco Use among High School Students in Kampala, Uganda: Questionnaire Study. Croatian Medical Journal, 45, 80-83.

[12] Kwamanga, D., Odhiambo, J. and Amukoye, E. (2003) Prevalence and Risk Factors of Smoking among Secondary School Students in Nairobi. East African Medical Journal, 80, 207-212. https://doi.org/10.4314/eamj.v80i4.8644

[13] Patel, P., Collin, J. and Gilmore, A.B. (2007) The Law Was Actually Drafted by Us But the Government Is to Be Congratulated on Its Wise Actions: British American Tobacco and Public Policy in Kenya. Tobacco Control, 16, e1. https://doi.org/10.1136/tc.2006.016071

[14] Townsend, L., Flisher, A.J., Gilreath, T. and King, G. (2006) A Systematic Literature Review of Tobacco Use among Adults 15 Years and Older in Sub-Saharan Africa. Drug and Alcohol Dependence, 84, 14-27. https://doi.org/10.1016/j.drugalcdep.2005.12.008

[15] Gathecha, G.K. (2014) Tobacco Control Research in Kenya: The Existing Body of Knowledge. Pan African Medical Journal, 17, 155. https://doi.org/10.11604/pamj.2014.17.155.2707

[16] WHO (2008) Report on the Global Tobacco Epidemic. The MPOWER Package. http://www.who.int/tobacco/global_interaction/tobreg/who_tsr.pdf

[17] John, M.K. and Bosire, R. (2013) Compliance with the Tobacco Control Act, 2007. In: Kenya: The Role of the Tobacco Control Board, University of Nairobi Press, Nairobi, 1-78. http://hdl.handle.net/11295/62582

[18] Mohamed, S.F., et al. (2018) Facilitators and Barriers in the Formulation and Implementation of Tobacco Control Policies in Kenya: A Qualitative Study. BMC Public Health, 18, 960. https://doi.org/10.1186/s12889-018-5830-x

[19] WHO (2016) Advisory Note: Banning Menthol in Tobacco Products. WHO Press, Geneva, 1-70.

[20] Brathwaite, R., Addo, J., Smeeth, L. and Lock, K. (2015) A Systematic Review of Tobacco Smoking Prevalence and Description of Tobacco Control Strategies in Sub-Saharan African Countries; 2007 to 2014. PLoS ONE, 10, e0132401. https://doi.org/10.1371/journal.pone.0132401 
[21] Ogwell, A., Aström, A. and Haugejorden, O. (2003) Socio-Demographic Factors of Pupils Who Use Tobacco in Randomly-Selected Primary Schools in Nairobi Province, Kenya. East African Medical Journal, 80, 235-241. https://doi.org/10.4314/eamj.v80i5.8693

[22] Atwoli, L., Mungla, P.A., Ngung'u, M.N., Kinoti, K.C. and Ogot, E.M. (2011) Prevalence of Substance Use among College Students in Eldoret, Western Kenya. BMC Psychiatry, 11, 34. https://doi.org/10.1186/1471-244X-11-34

[23] Masibo, P., et al. (2013) Prevalence and Determinants of Under- and Over-Nutrition among Adult Kenyan Women; Evidence from the Kenya Demographic and Health Survey 2008-09. East African Journal of Public Health, 10, 611-622.

[24] Komu, P., Dimba, E.A., Macigo, F.G. and Ogwell, A.E. (2009) Cigarette Smoking and Oral Health among Healthcare Students. East African Medical Journal, 86, 178-182. https://doi.org/10.4314/eamj.v86i4.46948

[25] Ndetei, D.M., Khasakhala, L.I., Mutiso, V., Ongecha-Owuor, F.A. and Kokonya, D.A. (2010) Drug Use in a Rural Secondary School in Kenya. Substance Abuse, 31, 170-173. https://doi.org/10.1080/08897077.2010.495313

[26] NACADA (2012) Rapid Situation Assessment of the Status of Drug and Substance Abuse in Kenya.

[27] Warren, C.W., Jones, N.R., Eriksen, M.P. and Asma, S. (2006) Patterns of Global Tobacco Use in Young People and Implications for Future Chronic Disease Burden in Adults. The Lancet, 367, 749-753. https://doi.org/10.1016/S0140-6736(06)68192-0

[28] Fong, G.T., Cummings, K.M., Borland, R., Hastings, G., Hyland, A., Giovino, G.A., Hammond, D. and Thompson, M.E. (2006) The Conceptual Framework of the International Tobacco Control (ITC) Policy Evaluation Project. Tobacco Control, 15, iii3-iii11. https://doi.org/10.1136/tc.2005.015438

[29] Ashley, D.L. and Backinger, C.L. (2012) The Food and Drug Administration's Regulation of Tobacco: The Center for Tobacco Products' Office of Science. American Journal of Preventive Medicine, 43, S255-S263.

https://doi.org/10.1016/j.amepre.2012.08.004

[30] Kenya National Bureau of Statistics (2015) KDHS Kenya Demographic and Health Survey 2014. Kenya National Bureau of Statistics, Nairobi. https://dhsprogram.com/pubs/pdf/fr308/fr308.pdf

[31] Okech, T.C. (2016) Devolution and Universal Health Coverage in Kenya: Situational Analysis of Health Financing, Infrastructure and Personnel. International Journal of Economics, Commerce \& Management, 4, 1-17. http://erepo.usiu.ac.ke/11732/3016

[32] Snow, R.W. and Marsh, K. (2010) Malaria in Africa: Progress and Prospects in the Decade since the Abuja Declaration. The Lancet, 376, 137-139. https://doi.org/10.1016/S0140-6736(10)60577-6

[33] Koh, H.K., Alpert, H.R., Judge, C.M., Caughey, R.W., Elqura, L.J., Connolly, G.N. and Warren, C.W. (2011) Understanding Worldwide Youth Attitudes towards Smoke-Free Policies: An Analysis of the Global Youth Tobacco Survey. Tobacco Control, 20, 219-225. https://doi.org/10.1136/tc.2010.038885

[34] Rigotti, N.A. (2002) Treatment of Tobacco Use and Dependence. The New England Journal of Medicine, 346, 506-512. https://doi.org/10.1056/NEJMcp012279

[35] Kibwage, J.K., Netondo, G.W., Odondo, A.J., Momanyi, G.M., Awadh, A.H. and Magati, P.O. (2014) Diversification of Household Livelihood Strategies for Tobacco 
Small-Holder Farmers: A Case Study of Introducing Bamboo in South Nyanza Region, Kenya. South Eastern Kenya University, Kitui County, 1-25.

[36] Giovino, G.A., Mirza, S.A., Samet, J.M. and Gupta, P.C. (2012) Tobacco Use in 3 Billion Individuals from 16 Countries: An Analysis of Nationally Representative Cross-Sectional Household Surveys. The Lancet, 380, 668-679.

https://doi.org/10.1016/S0140-6736(12)61085-X

[37] Jorenby, D.E., Leischow, S.J., Nides, M.A., Rennard, S.I., Johnston, J.A., Hughes, A.R., et al. (1999) A Controlled Trial of Sustained-Release Bupropion, a Nicotine Patch, or Both for Smoking Cessation. The New England Journal of Medicine, 340, 685-691. https://doi.org/10.1056/NEJM199903043400903

[38] Benowitz, N.L. (2008) Neurobiology of Nicotine Addiction: Implications for Smoking Cessation Treatment. The American Journal of Medicine, 121, S3-S10. https://doi.org/10.1016/j.amjmed.2008.01.015

[39] Hatsukami, D.K., Stead, L.F. and Gupta, P.C. (2008) Tobacco Addiction: Diagnosis and Treatment. The Lancet, 371, 2027-2038.

https://doi.org/10.1016/S0140-6736(08)60871-5

[40] Stead, L.F., Bergson, G. and Lancaster, T. (2008) Physician Advice for Smoking Cessation. Cochrane Database of Systematic Reviews, 2, Cd000165. https://doi.org/10.1002/14651858.CD000165.pub3

[41] Pauwels, R.A., Buist, A.S., Calverley, P.M., Jenkins, C.R. and Hurd, S.S. (2001) Global Strategy for the Diagnosis, Management, and Prevention of Chronic Obstructive Pulmonary Disease: NHLBI/WHO Global Initiative for Chronic Obstructive Lung Disease (GOLD) Workshop Summary. American Journal of Respiratory and Critical Care Medicine, 163, 1256-1276.

https://doi.org/10.1164/ajrccm.163.5.2101039

[42] Kong, G., Morean, M.E., Cavallo, D.A., Camenga, D.R. and Krishnan-Sarin, S. (2015) Reasons for Electronic Cigarette Experimentation and Discontinuation among Adolescents and Young Adults. Nicotine \& Tobacco Research, 17, 847-854. https://doi.org/10.1093/ntr/ntu257

[43] Ngaruiya, C., Abubakar, H., Kiptui, D., Kendagor, A., Ntakuka, M.W., Nyakundi, P. and Gathecha, G. (2018) Tobacco Use and Its Determinants in the 2015 Kenya WHO STEPS Survey. BMC Public Health, 18, 1223. https://doi.org/10.1186/s12889-018-6058-5

[44] Fiore, M.C., Jaén, C.R., Baker, T.B., Bailey, W.C., Benowitz, N.L., Curry, S.J., et al. (2009) Treating Tobacco Use and Dependence: 2008 Update: Clinical Practice Guideline. Respiratory Care, 53, 1217-1222.

[45] Zieleń, I., Sliwińska-Mossoń, M. and Milnerowicz, H. (2012) Drugs Used to Treat Nicotine Addiction. Przegląd Lekarski, 69, 1098-1102.

[46] Foulds, J. (2006) The Neurobiological Basis for Partial Agonist Treatment of Nicotine Dependence: Varenicline. International Journal of Clinical Practice, 60, 571-576. https://doi.org/10.1111/j.1368-5031.2006.00955.x

[47] GYTSC (2003) Differences in Worldwide Tobacco Use by Gender: Findings from the Global Youth Tobacco Survey. Journal of School Health, 73, 207-215. https://doi.org/10.1111/j.1746-1561.2003.tb06562.x

[48] Mokdad, A.H., Marks, J.S., Stroup, D.F. and Gerberding, J.L. (2004) Actual Causes of Death in the United States, 2000. JAMA, 291, 1238-1245.

https://doi.org/10.1001/jama.291.10.1238

[49] WHO (2013) Report on the Global Tobacco Epidemic: Enforcing Bans on Tobacco 
Advertising, Promotion and Sponsorship. World Health Organization, Geneva, 1-106. https://tobaccocontrol.bmj.com/content

[50] Bates, C., Fagerström, K., Jarvis, M.J., Kunze, M., McNeill, A. and Ramström, L. (2003) European Union Policy on Smokeless Tobacco: A Statement in Favour of Evidence Based Regulation for Public Health. Tobacco Control, 12, 360-367.

https://doi.org/10.1136/tc.12.4.360 